\title{
Unusual Branching Pattern of the Lateral Cord of the Brachial Plexus Associated with Neurovascular Compression Case report
}

"Hitendra K. Loh, Shikha Singh, Rajesh K. Suri

$$
\begin{aligned}
& \text { تفرع غير طبيعي للحبل الفرعي للضفيرة العضدية مصاحبة للإنضغاط } \\
& \text { العصبي الوعائي } \\
& \text { تقرير الحالة }
\end{aligned}
$$

هتندرة كومار لوه، شيخا سينغ، راجيش كومار سوري

\begin{abstract}
AB STRACT: The brachial plexus consists of a network of nerves that innervates the upper limbs and its musculature. We report a rare formation of the lateral cord of the brachial plexus observed during the dissection of a 47-year-old male cadaver at the Department of Anatomy, Vardhman Mahavir Medical College, New Delhi, India, in 2016. The lateral cord was exceptionally long with twin lateral pectoral nerves and twin lateral roots of the median nerve. The proximal lateral root of the median nerve was thin in comparison to the medial root of the median nerve. The distal lateral root of the median nerve was thicker and followed an unusual course through the coracobrachialis muscle. In the lower third of the arm, the median nerve and the brachial artery-along with its vena comitans-spanned through the brachialis muscle. Surgeons, anaesthesiologists, radiologists and anatomists should be aware of such anatomical variations as they may result in neurovascular compression.
\end{abstract}

Keywords: Anatomic Variation; Dissection; Brachial Plexus; Pectoral Nerves; Median Nerve; Musculocutaneous Nerve; Case Report; India.

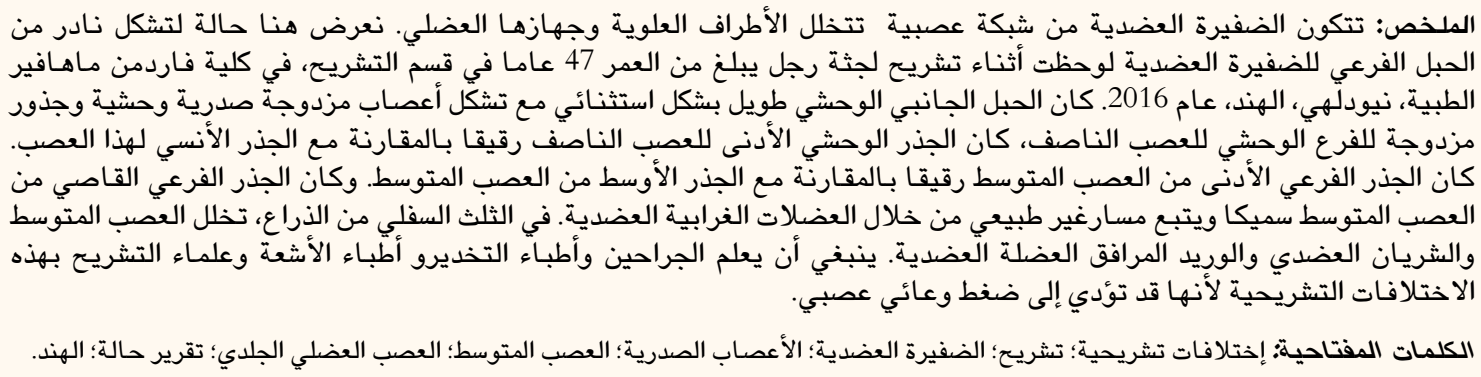

$\mathrm{T}$

He bRachial plexus is a Network of multiple nerves which innervates the upper arm and the muscles which control movement of the shoulder girdle. ${ }^{1}$ The union of the anterior divisions of the upper and middle trunk in the infraclavicular part of the brachial plexus forms the lateral cord (LC). The first branch of the LC, the lateral pectoral nerve (LPN), pierces the clavipectoral fascia to supply the pectoralis major muscle. ${ }^{1}$ In addition, the LPN gives rise to a communicating twig to the medial pectoral nerve across the axillary artery, through which it supplies the pectoralis minor muscle. The next branch, the musculocutaneous nerve $(\mathrm{McN})$, runs obliquely downwards to pierce and supply the coracobrachialis (CB) muscle. ${ }^{1}$ Inferiorly, the $\mathrm{McN}$ also supplies the biceps brachii (BB) and the brachialis muscles before forming the lateral cutaneous nerve of the forearm. The third branch is the lateral root of the median nerve (MN), which is a continuation of the LC; this joins the medial root to enfold the axillary artery and forms the MN. ${ }^{1}$ Clavicular and sternal attachments of the pectoralis major muscle are supplied by the medial pectoral nerve, whereas the inferior third and costo-abdominal insertions of the pectoralis major muscle are innervated by the LPN. ${ }^{2}$

Various arterial, neural and muscular variations in the upper limbs have been described in the literature. ${ }^{3-5}$ However, anatomical variations in the course 


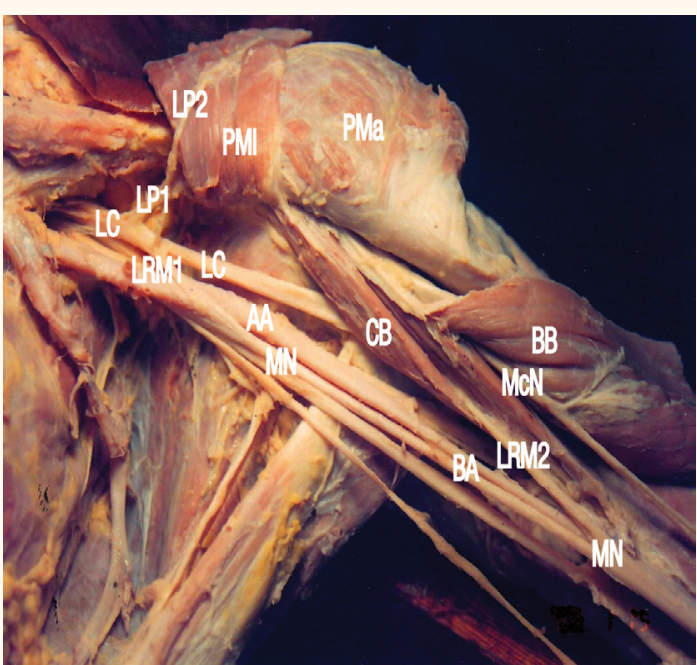

Figure 1: Photograph from the anterior view of the dissected axillary fossa and the upper arm of an embalmed 47-year-old male Indian cadaver showing an unusual variation of the left brachial plexus. The biceps brachii has been cut and reflected.

$L P 2=$ distal lateral pectoral nerve; $P M i=$ pectoralis minor $P M a=$ pectoralis major $: L P 1=$ proximal lateral pectoral nerve; $L C=$ lateral cord $L R M 1=$ proximal lateral root of the median nerve; $A A=$ axillary artery; $C B=$ coracobrachialis; $B B=$ biceps brachii: $M N=$ median nerve; $M c N=$ musculocutaneous nerve $B A=$ brachial artery; $L R M 2=$ distal lateral root of the median nerve.

and branching patterns of the distal part of the brachial artery are extremely rare. These may include variations in the course beneath the supracondylar process, through the brachialis or pronator teres muscles or a low division under the pronator teres muscle., ${ }^{4,6}$ Awareness of neural variations in the brachial plexus region is essential for surgeons, anaesthesiologists, radiologists and anatomists. The presence of anatomic variations in the peripheral nervous system may also explain unusual clinical findings or symptoms. ${ }^{7}$ This case describes an interesting and rare variant of the LC of the brachial plexus with a duplication of the $\mathrm{LPN}$, twinning of the lateral root of the $\mathrm{MN}$, the absence of the medial pectoral nerve, an atypical formation of the $\mathrm{MN}$ and an abnormal course of the $\mathrm{McN}$.

\section{Case Report}

A routine undergraduate medical dissection of an embalmed 47-year-old male Indian cadaver took place at the Department of Anatomy, Vardhman Mahavir Medical College, New Delhi, India, in 2016. During the dissection, an unusual variation of the left brachial plexus was noted [Figure 1]. The LC was unusually long at $8.9 \mathrm{~cm}$ and gave rise to a double LPN. The proximal LPN (LP1) was thicker, pierced the clavipectoral fascia and entered the superficial surface

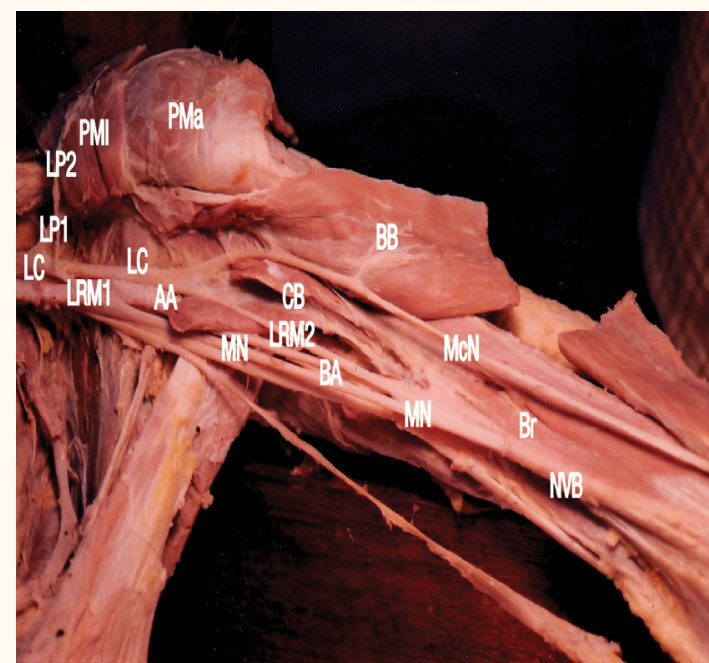

Figure 2: Photograph from the anterior view of the dissected axillary fossa and the upper arm of an embalmed 47-year-old male Indian cadaver. The coracobrachialis muscle has been partially removed to expose the distal lateral root of the median nerve. The biceps brachii has been cut and reflected.

$P M a=$ pectoralis major $P M i=$ pectoralis minor $\quad L P 2=$ distal lateral pectoral nerve; $L P 1=$ proximal lateral pectoral nerve; $B B=$ biceps brachii $: L C=$ lateral cord $L R M 1=$ proximal lateral root of the median nerve; $A A=$ axillary artery; $C B=$ coracobrachialis $M c N=$ musculocutaneous nerve; $M N=$ median nerve; $L R M 2=$ distal lateral root of the median nerve; $B A=$ brachial artery; $\mathrm{Br}=$ brachialis; $N V B=$ lower part of the neurovascular bundle.

of the pectoralis major muscle. The distal LPN (LP2) was slender, branched one centimetre away from the LP1 and entered the pectoralis minor muscle from its deeper aspect. The LC also supplied double lateral roots of the MN. The proximal lateral root of the $\mathrm{MN}$ (LRM1) was slender and originated $3.7 \mathrm{~cm}$ from the formation of the LC. The distal lateral root of the MN (LRM2) measured $9.2 \mathrm{~cm}$ in length, was significantly thicker and arose $9 \mathrm{~cm}$ from the formation of the LC [Figure 2].

Upon reaching the $\mathrm{CB}$, the LRM2 pierced the muscle belly and joined the MN in the mid-arm. At the formation of the MN, the LRM1 was very thin in comparison to its medial root, whereas the LRM2 was significantly thicker. The proximal course of the McN passed between the $\mathrm{BB}$ and $\mathrm{CB}$ muscles and traversed between the $\mathrm{BB}$ and brachialis muscles distally to continue as the lateral cutaneous nerve of the forearm. The MN and the brachial artery, flanked by its vena comitans, were wrapped in a common fascial sheath and traversed through the brachialis muscle in the lower third of the arm. The intramuscular course of this neurovascular bundle was $5.9 \mathrm{~cm}$ in length and the medial pectoral nerve was absent. The anatomy of the brachial plexus on the right side of the cadaver was normal. All measurements were recorded using a thread to follow the course of the nerves. 


\section{Discussion}

The current report describes a case in which there were two LPNs present: the LP1, which supplied the pectoralis major muscle after piercing the clavipectoral fascia, and the LP2, which supplied the pectoralis minor directly. The occurrence of a duplicate LPN arising from the anterior division of the upper and middle trunk instead of the LC has been previously reported in the literature. ${ }^{8}$ A common trunk of origin of the medial pectoral nerve and the LPN from the middle trunk of the brachial plexus has also been documented. ${ }^{9}$ Awareness of variations in the anatomy and course of the pectoral nerves is crucial during surgery; for example, when using pectoral muscle flaps during breast surgeries or when the brachial plexus pectoral nerves are transferred to supply a paralysed arm during traction injury repairs. ${ }^{10,11}$

Cases in which the LC of the brachial plexus pierces the $\mathrm{CB}$ muscle and divides into the $\mathrm{McN}$ and the lateral root of the $\mathrm{MN}$ are very rare. ${ }^{4}$ In the present case, the LC was longer than usual and gave rise to the LP1, LP2 and LRM1 before dividing into the $\mathrm{McN}$ and the LRM2 upon reaching the CB muscle. The $\mathrm{McN}$ then continued between the $\mathrm{BB}$ and $\mathrm{CB}$ muscles in the arm instead of piercing the $\mathrm{CB}$ muscle; hence, the $\mathrm{MN}$ presented with double lateral roots (the LRM1 and LRM2). Moreover, the LRM1 was very thin compared to the LRM2 which joined the MN in the mid-arm. This difference in thickness, along with the abnormal course of the LRM2 through the CB, is clinically significant. Durgesh et al. reported a case in which the $\mathrm{McN}$ passed along the medial edge of the $\mathrm{CB}$ muscle without penetrating it. ${ }^{12}$ Jamuna et al. reported a case whereby the $\mathrm{McN}$ joined the $\mathrm{MN}$ after piercing the $\mathrm{CB}$ muscle and Abhaya et al. reported a rare case in which the $\mathrm{LC}$ directly pierced the $\mathrm{CB}$ before dividing into the $\mathrm{McN}$ and the lateral root of the $\mathrm{MN}^{3,13}$ Abnormal variations in the formation and course of the $\mathrm{McN}$ are important as they may affect the outcomes of surgical interventions for shoulder joint trauma, flap dissections, explorative procedures, axillary blocks and post-traumatic evaluations. ${ }^{14}$

Anatomical variations in the brachial plexus arise during embryonic development. In a developing embryo, the upper limb bud appears by the $27^{\text {th }}$ gestational day. ${ }^{15}$ After the fifth gestational week, motor axons originating from the spinal cord enter the limb buds and the brachial plexus forms as a single radicular cone by the $34-35^{\text {th }}$ gestational day. Following this, the brachial plexus splits into ventral and dorsal segments and the roots of the $\mathrm{MN}$ and ulnar nerve are derived from the ventral segments. ${ }^{15}$ By the $48^{\text {th }}$ gestational day, the localisation of the upper limb nerves is established. Communication between the $\mathrm{McN}$ and the MN can therefore be attributed to their common embryological derivation during the development of the brachial plexus. ${ }^{15}$ Altered signalling amongst mesenchymal cells and neuronal growth cones during the union of the brachial plexus cords has been previously found to result in variations in neural anatomy. ${ }^{16}$

In the current case, there were two potential sites which may have resulted in neurovascular compression in the arm: the entrapment of the LRM2 through the $\mathrm{CB}$ muscle or a potential injury to the LRM2 in the middle arm and the irregular course of the MN and the brachial artery through the brachialis muscle in the lower arm. ${ }^{17}$ Entrapment injuries in the arm may lead to paresthaesia along the preaxial border of the forearm, weak elbow flexion and other manifestations of a $\mathrm{MN}$ injury. ${ }^{17}$ Entrapment of the $\mathrm{MN}$ and brachial artery is widely studied. ${ }^{18}$ However, it is rare for anatomical variations to occur in the distal part of the brachial artery in the muscles of the arm and forearm. ${ }^{4,6}$

The $\mathrm{MN}$ and the brachial artery cross the mid and lower arm as the main neurovascular complex. ${ }^{19}$ However, their proximity to the medial intermuscular septum and the medial side of the $\mathrm{BB}$ and brachialis muscles make them vulnerable to various entrapment syndromes; moreover, while $\mathrm{MN}$ entrapment can occur at several sites from the upper arm to the carpal tunnel, it is especially common at sites below the elbow. ${ }^{20}$ The $\mathrm{MN}$ and brachial artery can also be compressed by the lacertus fibrosus in the lower arm. ${ }^{21}$ This is critical as the nerve can lose its suppleness and become stretched by joint movement when it becomes attached to adjacent structures. Although nerve compression is easily managed and can be resolved by releasing the neurovascular structure from the entrapment, clinicians should be aware of potential entrapment injuries as they can lead to neuropathy, loss of muscle strength and atrophy. ${ }^{22}$

\section{Conclusion}

This case describes the unusual occurrence of a double LPN, double lateral roots of the MN and an anomalous course of the $\mathrm{McN}$. These rare variations are potential sites for neural or neurovascular compression in the middle and distal arm, respectively. Radiologists, neurovascular surgeons, anaesthesiologists and anatomists should consider such potential variations when dealing with the brachial plexus region. 


\section{References}

1. McMinn RM. Last's Anatomy: Regional and applied, 8th ed. London, UK: Churchill Livingstone, 1990. Pp. 68-9.

2. Cunningham DJ, Romanes GJ. Cunningham's Textbook of Regional Anatomy, 11th ed. London, UK: Oxford University Press, 1972. P. 308

3. Abhaya A, Khanna J, Prakash R. Variation of the lateral cord of brachial plexus piercing coracobrachialis muscle. J Anat Soc India 2003; 52:168-70

4. Bergman RA, Afifi AK, Myiauchi R. Illustrated encyclopedia of human anatomic variation. From: www.anatomyatlases.org/ AnatomicVariants/AnatomyHP.shtml Accessed: Nov 2016.

5. Vollala VR, Nagabhooshana S, Bhat SM, Potu BK, Rodrigues V, Pamidi N. Multiple arterial, neural and muscular variations in upper limb of a single cadaver. Rom J Morphol Embryol 2009, 50:129-35.

6. Wysiadecki G, Polguj M, Haładaj R, Topol M. Low origin of the radial artery: A case study including a review of literature and proposal of an embryological explanation. Anat Sci Int 2016. doi: 10.1007/s12565-016-0371-9.

7. Thwin SS, Zaini F, Than M, Lwin S, Myint M. Unusual variations of the lateral and posterior cords in a female cadaver. Singapore Med J 2012; 53:e128-30.

8. Bhanu SP, Sankar DK, Susan PJ. Formation of median nerve without the medial root of medial cord and associated variations of the brachial plexus. Int J Anat Var 2010; 3:27-9.

9. Khullar M, Sharma S, Khullar S. Multiple bilateral neuroanatomical variations of the nerves of the arm: A case report. Int J Med Health Sci 2012; 1:75-84.

10. David S, Balaguer T, Baque P, de Peretti F, Valla M, Lebreton E, et al. The anatomy of the pectoral nerves and its significance in breast augmentation, axillary dissection and pectoral muscle flaps. J Plast Reconstr Aesthet Surg 2012; 65:1193-8. doi: 10.1016/j.bjps.2012.03.032
11. Samardzic M, Rasulic LG, Grujicic DM, Bacetic DT, Milicic BR. Nerve transfers using collateral branches of the brachial plexus as donors in patients with upper palsy: Thirty years' experience. Acta Neurochir (Wien) 2011; 153:2009-19. doi: 10.1007/ s00701-011-1108-0.

12. Durgesh V, Rao RR. Musculocutaneous nerve revisited. Int J Basic Appl Med Sci 2013; 3:34-6.

13. Jamuna M, Amudha G. A cadaveric study on the anatomic variations of the musculocutaneous nerve in the infraclavicular part of the branchial plexus. J Clin Diagn Res 2011; 5:1144-7.

14. Mavishettar SM, Iddalagave S. Musculocutaneous nerve and its variations. Int J Gen Med Pharm 2013; 2:53-64.

15. Uyaroğlu FG, Kayalioğlu G, Ertürk M. Anastomotic branch from the median nerve to the musculocutaneous nerve: A case report. Anat 2008; 2:63-6. doi: 10.2399/ana.08.063.

16. Sanes DH, Reh TA, Harris WA. Axon growth and guidance. In: Development of the Nervous System, 3rd ed. San Diego, California, USA: Academic Press; 2011. Pp. 105-42. doi: 10.10 16/B978-0-12-374539-2.00009-4.

17. Neal S, Fields KB. Peripheral nerve entrapment and injury in the upper extremity. Am Fam Physician 2010; 81:147-55.

18. Bilecenoglu B, Uz A, Karalezli N. Possible anatomic structures causing entrapment neuropathies of the median nerve: An anatomic study. Acta Orthop Belg 2005; 71:169-76.

19. McNamara B. Clinical anatomy of the median nerve. Adv Clin Neurosci Rehabil 2003; 2:19-20.

20. Birch R. Operating on peripheral nerves. In: Surgical Disorders of the Peripheral Nerves, 2nd ed. London, UK: Churchill Livingstone, 2011. Pp. 231-302. doi: 10.1007/978-1-84882108-8 7 .

21. Kumar H, Das S, Gaur S. Case report: Entrapment of the median nerve and the brachial artery by the lacertus fibrosus. Arch Med Sci 2007; 3:284-6.

22. Green DP, Hotchkiss RN, Pederson WC. Green's Operative Hand Surgery, 4th ed. Philadelphia, Pennsylvania, USA: Churchill Livingstone, 1999. Pp. 1417-22. 